\section{sciendo}

Management Consulting Journal

Volume 5.1 | January 2022

DOI: $10.2478 / \mathrm{mcj}-2022-0004$

ISSN: 2631-987X

(C) 2022 Karol Szlichcinski. This is an open access article licensed under the Creative Commons Attribution-NonCommercialNoDerivs License (http://creativecommons.org/licenses/by-nc-nd/3.0/).

\title{
What Management Consultants Want from Academics
}

\author{
Karol Szlichcinski, Centre for Management Consulting Excellence
}

\begin{abstract}
The Centre for Management Consulting Excellence (CMCE) carried out some exploratory research into how consultants access and use outputs of academic research in their work. We investigated:
\end{abstract}

- The extent to which consultants used outputs of academic research in their work;

- The sources used by consultants to access the outputs of academic research;

- The benefits and disadvantages for consultants of the outputs of academic research;

- Consultants' experiences in working with academics;

- How consultants used academic outputs in ther continuing professional development (CPD) activities.

The research found that academic work contributes to the knowledge base that consultants draw on in three main ways:

1. It is a source of ideas underlying major types of consulting interventions and of widely used consulting tools;

2. Outputs of academic work provide information that can be used on specific projects;

3. Academic outputs can contribute to consultants' CPD. 


\section{Introduction}

The Centre for Management Consulting Excellence (CMCE) carried out some exploratory research into how consultants access and use outputs of academic research in their work. Our research consisted of some initial desk research into the origins of a number of consulting tools and interventions, an online survey, telephone and face-to-face interviews, and two focus groups. After developing and piloting the survey questionnaire, links to the questionnaire were distributed in an online newsletter sent to a mailing list of over 500 recipients. We collected 24 completed questionnaires, a response rate of $4.8 \%$. We also carried out 17 phone or face-to-face interviews. Seven of these were with people who completed the online survey, so that we had inputs from 34 individuals. Our sample size was too small to give reliable quantitative findings, but enabled us to gauge the relative importance of various factors. The interviews provided some rich qualitative material. The focus groups discussed the survey and interview findings.

\section{Academic Work Contributions to Consulting Practice: Three Ways}

Management consulting work typically combines generic consulting skills with specialist expertise in a particular organisational function, e.g. finance or IT, and often detailed knowledge of one or more economic sectors. (The exception is strategy consulting which typically requires a general appreciation of all organisational functions coupled with highly developed analytic expertise and often sector knowledge.) To support their work consultants need to access sources of knowledge relating both to generic consulting skills and to their particular function and sector specialisms.

Academic work contributes in three main ways to the knowledge base that consultants draw on:

1. It is a source of ideas underlying major types of consulting interventions and of widely used consulting tools;

2. Outputs of academic work provide information that can be used on a specific project;

3. Academic outputs can contribute to consultants' continuing professional development (CPD).

Widely used consulting methods and tools originally derived from academic work include Porter's Five Force Model, the Balanced Scorecard and Business Process Reengineering. Only a tiny fraction of published academic papers have contributed widely to adopted methods and tools, and many consultants are unaware of the academic roots of these interventions. The second and third ways in which academic work contributes to consultants' knowledge base are addressed in the following sections of this paper.

The distinction between work produced by academics and non-academics is not clearcut. Some of the most useful outputs are provided by people who combine academic work with a role in another sector or with a consulting practice, or who have 
moved into academia from consulting or another sector. Their practical experience undoubtedly helps them produce outputs of use to practitioners.

\section{Most Consultants Have Used Outputs of Academic Research in Their Work}

Most of the consultants who participated in our research had used outputs of academic research in their work (The work was typically projects for clients, but many of our respondents also mentioned preparing thought leadership materials.). Most commonly used were outputs of general business, management, or consulting interest, but sectorspecific content and content specific to an organisational function, e.g. finance or marketing, were also popular. Almost all of the consultants who had not used outputs of academic research were one-person businesses.

For the consultants who participated in our research, the most common source of academic outputs was academic journal articles (in print or online), but many of our research participants had worked jointly with academics on a project. Consultants also benefited from reports and presentations specifically commissioned by consultancy firms from individual academics or university departments. The most commonly quoted benefit of academic outputs was the credibility of the source. Academic outputs were also seen as a source of useful conceptual models, frameworks, tools, or techniques, and as providing access to the latest thinking.

Our respondents also saw some disadvantages to academic outputs. Some academic outputs were found to be less useful than they might have been because they were too complex to communicate to a client, too long term for a client's requirements, not specific enough, or difficult to read or understand. Academic writing is a significant barrier for some consultants and their clients.

The majority of consultants could think of a time when they might have found outputs of academic research useful but did not use them. The main reasons were that they did not know that relevant research was available, they could not find material relevant to a specific context, or the cost of academics' fees. The cost of fees related to hiring academics to provide inputs or carry out projects, but also reflected the cost of accessing academic journal articles for people outside the academic environment.

Most of the consultants participating in our research had worked with a university department, employee, or student in their consultancy work, most commonly:

- Providing placements for students to carry out projects or give them work experience, or working with students on placements with clients;

- Contracting a senior academic to provide expert input;

- Contracting a university department or individual academic to carry out a project.

The positive aspects of these working arrangements were unsurprising. Typically they were characterised by useful and/or interesting inputs, good working relationships, and stimulating team members. 
The problems encountered with these working arrangements are more informative. The most frequently encountered problem was long drawn-out timescales for completing work and/or missing deadlines. Timescales for finishing consulting projects are often not compatible with academics fitting contributions in between other commitments, and project deadlines are sometimes not treated as seriously in the academic world as they are in business.

Mismatches in timescales may also betray a fundamental difference in ways of working, as one senior partner at a major consulting firm pointed out: consultants typically form hypotheses very quickly and then collect evidence to support them. This is not the same as the scientific method.

More surprising was the complaint that outputs did not meet the standards required for consultancy. The main issues here were writing style and skills; consultants are used to distilling the conclusions of greatest interest to top management and presenting them in a highly condensed and structured form, typically according to the Minto pyramid principle. This is a far cry from most academic writing, which in its characteristic form of academic journal articles requires a completely different structure and more extended treatment of a topic.

There were also specific problems relating to student placements. Several of our respondents reported that students did not provide useful outputs or that they required too much supervision. Other problems consultants encountered in working with academics included poor project management and universities' inflexible contracting arrangements; for example, high margins allocated for overheads made cooperation uneconomic.

\section{Consultants Rely on the Outputs of Academic Research for Their Continuing Professional Development}

Consultants need to keep their expertise up to date, both in their area of specialist knowledge and in general consulting capabilities. As well as learning on projects they carry out, most consultants engage in CPD activities. The most common ways in which consultants keep their professional expertise up to date are reading (both online and offline materials), attending seminars, conferences and webinars, and conversations with professional colleagues and clients.

General management and business books, and articles and websites written for a professional or general audience are the most popular CPD reading materials. Publications by consulting firms and materials relating to consultants' professional or technical specialisms are also popular. Only a third of consultants said they read academic journals for their CPD. Interviewees' comments indicated that in many cases this referred to Harvard Business Review, which is not usually regarded as a scholarly journal. A few interviewees mentioned bona fide academic journals relating to their consulting specialism, but the proportion of consultants reading peer reviewed academic journals for CPD appears to be very small. 
Nevertheless a substantial majority of consultants say that the materials they read draw on the findings of academic research at least some of the time. For example, the management books and articles they read may be written by academics popularising their research or by specialist journalists who draw on academic research. When survey respondents were asked to name books, articles, or reports based on academic research that they found particularly useful or insightful, more people mentioned books than articles or other publications. It seems that books are an effective vehicle for communicating the findings of academic research to consultants.

Consultants are most likely to attend seminars, conferences, and webinars organised by professional and learned societies, universities, and business schools, and commercial conference organisers. Most respondents said that the seminars, conferences and webinars that they attended presented the findings of academic research at least some of the time. Not all of these events featured academics as speakers, but presenters drew on the findings of academic research to a greater or lesser extent. 